\title{
On the penetration of daylight in the water of the lake of geneva
}

\author{
MM. Fol \& ED. Sarasin
}

To cite this article: MM. Fol \& ED. Sarasin (1885) On the penetration of daylight in the water of the lake of geneva, Philosophical Magazine Series 5, 19:116, 70-72, DOI: $10.1080 / 14786448508627648$

To link to this article: http://dx.doi.org/10.1080/14786448508627648

曲 Published online: 29 Apr 2009.

Submit your article to this journal $\sqsubset \pi$

Џ Article views: 2

Q View related articles $\square$ 
In this, the glass compensating prism, instead of being mounted separately, is cemented upon one of the terminal faces of the compound spar-prism; the angle of this latter, and also of the other terminal face, being suitably modified.

This seems distinctly preferable to the original arrangement, for several reasons.

1. The total length of the compound prism is rather less, being scarcely more than twice its breadth.

2. The field is rather larger, so that the prism can be used over microscope eye-pieces (A and B) without Fig. 2.

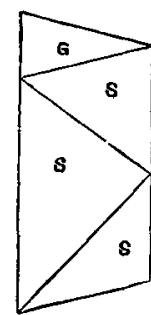
any of the field of riew being cut off.

3. The whole arrangement is more compact, all the components being firmly cemented together, and therefore not liable to accidental displacement.

4. There is less loss of light by reflection, the reflecting surfaces being reduced to two.

A ray of light entering the prism in a direction parallel to its axis is divided into two rays ; one of which, on emergence, follows a course parallel to that of the original incident ray, and is practically free from distortion and colour; the other ray is deviated to the extent of about $59^{\circ} 30^{\prime}$ (for yellow sodium-light), being, of course, strongly coloured and distorted. The angular separation is so great that this latter ray does not interfere with ordinary observations.

I hope that the prism, which has cost me much time and labour, will meet with the approval of the Society, and take a place as a useful accessory to the microscope and other optical instruments.Journal of the Royal Microscopical Society, August 1884.

\section{ON THE PENETRATION OF DAYLIGHT IN THE WATER OF THE LAKE}

OF GENEVA. BY MM. FOL AND ED. SARASIN.

Questions relating to the absorption of light by more or less thick layers of the very pure water of the Lake of Geneva have been the object of a series of experiments, undertaken by a Commission of the Société de Physique et d'Histoire naturelle of Geneva, on the incentive, and under the direction, of M. Louis Soret*.

We have been charged more particularly to examine, by means of photography, the extreme depth which daylight reaches. Our experiments consisted in exposing a photographic plate at various depths in that part of the lake where the water is deepest.

We used Monckhoven's rapid gelatino-bromide plates. They were placed in a special apparatus designed by one of us for these experiments $\uparrow$. It consists of a brass photographic back, the two

* Comptes Rendus, March 10, 1884, p. 624, and Archives des Sciences physiques et naturelles, vol. xi. p. 327, vol. xii. p. 158, 1884.

$\uparrow$ This apparatus was constructed according to the designs and instructions of M. Fol by the Société génevoise d'instruments de Physique. 
slides of which are closed by the action of a pair of levers joined like scissors and drawn by a weight; they separate by the action of an antagonistic spring, as soon as the weight of the lead in touching the bottom ceases to act on the levers. Knowing the depth, we can regulate the length of the line by which the weight is suspended to the apparatus, so as to have the photographic plate exposed in a horizontal position, at a given distance below the surface of the water. After a given exposure the apparatus is withdrawn, and rapidly closes under the action of the weight. The time of exposure was ten minutes in all cases. The development was made with the normal oxalate-of-iron developer, which was caused to act uniformly for ten minutes on each plate. They were all of the same lot, and therefore coated with the same emulsion*.

The experiments were made in front of Evian, where the lake has over a large surface a depth of 315 metres. Dr. Marcet was kind enough to place at our disposal on two occasions his steamyacht, the 'Heron.' Professor Forel, of Morges, had the goodness not only to lend us his sounding-line, but also to accompany us, and help us with his advice and his experience.

On the 16th of August, in calm weather and with a brilliant sun, we exposed:-

1. At 237 metres deep two plates, one at half-past twelve and the other at seven minutes past one.

2. At 113 metres a plate at twenty minutes after two.

3. At 300 metres deep ( 15 metres from the bottom) a plate at fortyfour minutes past two.

On the 23rd of September, 1884, in cloudy, but fine weather, the clouds slight and rather luminous, light wind varying from east to north, we exposed :-

4. At 147 metres a plate at 1 o'clock.

5. "170 " " 26 minutes past 2 .

6. " $113 \quad " \quad " 303$ " 3 .

7. "90.5 " " 34 " 3 .

As a comparison, we exposed on the 15 th of August at 10 p.m., on a clear night, but without moon :-

8. A plate in the open air for ten minutes.

9. " " five "

On developing, "it was found that the plate 3 (300 metres deep) had received no luminous impression whatever. The same was the case with plate 1 . Plate 5 at 170 metres was slightly clouded, almost like plate 9 , which was exposed at night for 5 minutes. Plate 4 at 147 metres had been slightly acted on, more so than the plate which had been exposed at night for ten minutes. Of the two plates at 113 metres, the plate 6 of the

* Preliminary experiments in rather shallow water showed that the apparatus worked as well as could be desired, and that when closed it could be left in full sunlight without any light getting to the plate. During exposure the glass was uppermost and towards the light. On this side characters and numbers were traced in black varnisl. The sharpness with which these signs were produced in white on the developed plate, the purity of the edges of the image, which, restricted by the separation of the covering plates, only extended to the middle of the sensitive layer, prove that light could not penetrate accidentally. 
second day was strongly blackened, while plate 2 of the furst day was no more affected than plate 4 of the second day, Finally, plate 7, exposed at 90 metres, was so acted upon that the lines which had been traced on the back were only imperfectly seen on the dark ground of the developed layer.

Comparing the results obtained on the two days of the experiments, we are struck by the fact that the photographic action was greater on the 231 d September than on the 16th August.

We are thus led to conclude from these first attempts;

1. That daylight penetrates into the water of the Lake of Geneva to a depth of 170 metres, and probably further; that at this depth the illumination in full daylight is just comparable to that which we observe on a fine night when there is no moon.

2. That at 120 metres the light is still very strong.

3. That in September, in cloudy weather the light penetrates in larger quantity and to a greater depth than in August, in perfectly bright weather. Further experiments will have to decide whether this difference is to be attributed to the greater transparency of water in autumn and in winter, which the experiments of M. Forel* have put beyond doubt, or whether the light diffused from the clouds penetrates further than the more or less oblique rays of the sun.

Previous to our experiments, M. Asper $t$ had exposed gelatinobromide plates in the Lake of Zurich at depths varying from 40 to 90 metres. He immersed them at night, and withdrew them the following night. But the darkest night is still bright for a rapid gelatino-bromide plate. Our experiments seem then to be made under more trying circumstances. We intend to pursue these experiments in the summer of 1885 .

We are desirous also, if possible, of making analogous experiments in the sea, where the greater transparency of the water leads to the supposition that the extreme limit of the luminous rays is at a still lower level.

In this respect satisfactory data are wanting, for the experiments of the cruise of the 'Porcupine' have remained in the state of project, as the apparatus devised by Sir W. Siemens refused to act. The depth to which daylight penetrates in the sea is therefore still to be found.-Comptes Rendus, Nov. 10, 1884.

* M. Forel investigated from 1873 the transparency of the waters of the Lake of Geneva by a photographic method; he employed, however, albuminized silver paper, which is less sensitive than gelatino-bromide. $\mathrm{He}$ immersed the sheets at night at various depths, and took them out after one or several twenty-four hours. This method gave for the limit of absolute darkness approximately 45 metres in summer and 100 metres in winter. The greater abundance of aquatic powders during summer, which is the cause of the greater opacity, is due to the thermal stratification of water during the hot season, from which results the power of holding in suspension powders of different densities (Archives des Sciences physiques et naturelles, vol. lix. p. 137, 1877).

$\dagger$ Archives des Sciences physiques et naturelles, vol. vi. p. 318, 1881. 